\title{
Assessment of Anti-Mullerian Hormone and Anti Ovarian Antibody in the Sera of Patients with Polycystic Ovarian Syndrome in AL-Najaf Al-Ashraf Province
}

\author{
Abbas Sahib Fakhar Al-Naffakh ${ }^{1}$, Farhan Abood Risan ${ }^{1}$ \\ ${ }^{I}$ Middle Technical University/College of health and medical technology/Baghdad
}

\begin{abstract}
Polycystic ovarian syndrome(PCOS)is the most common endocrinopathy,that affects 5 to $20 \%$ of women in age of(12-45year)and cause a widespread of reproductive disorder in women and it is a major cause of hirsutism, acne, hormonal disturbance and infertility. Women with PCOS may associated with health conditions obesity,amenorrhea, oligomenorrhea,hyperandrogenemia and insulin resistance. The PCOS patients are with increased risk for type 2diabetes mellitus, diabetic complications,dyslipidemia and cardiovascular disease .
\end{abstract}

Objective: Aim of the study to investigate the pathogenicity,disease severity and early diagnosis roles antiMullerian hormone and anti-ovarian antibody in ladies with PCOS.

Conclusion: Polycystic ovarian syndrome was related to the increase level of AMH in different age of PCOS patients, which comprised 55.0\% in PCOS patients that cause defect in ovulation and resulting fertility problem, while no relationship between anti-ovarian antibody and patients with PCOS.

Key words: $A M H, A O A, P C O S$ and infertility.

\section{Introduction}

Polycystic ovarian syndrome(PCOS)is a common and complex endocrine issue and hormonal abnormalities which influences whole body,that affected 5 to $20 \%$ of regenerative age ladies, occurred in age of(12-45)year, and it is a main reason for hirsutism and fertility problem ${ }^{(1)}$. PCOS is more typical than other conceptive infection; it is related with metabolic issue,for example,type 2 diabetes mellitus,dyslipidemia,hypertension and expanded risk of cardiovascular disease ${ }^{(2)}$.

The investigators between young adult and adolescent patients with PCOS found a few phenotypic differences, where the more severe component of the phenotype was in young adults was obesity,with the mean body mass index(BMI)and prevalence of obesity and morbid obesity being higher in young adult compared with adolescent patients ${ }^{(3)}$. The etiology of PCOS not clear,but rather numerous elements might be related with PCOS, which include obesity, hyperandrogenism, insulin resistance that lead to compensatory hyperinsulinemia , increment discharge of luteinizing hormone (LH) and disappointment ovarian follicular improvement because of expanded follicular advancement blocker paracrine factor, such as anti mullerian hormone $(\mathrm{AMH})$ that produce from granulosa cell of follicles in size under 8 $\mathrm{mm}^{(4)}$.

The diagnosis of PCOS in ladies is ordinarily as indicated by the European society of human reproduction and embryology/American society of reproductive medicine( ESRHE/ASRM) criteria known as Rotterdam criteria, which rely upon nearness at any rate two of three highlights of oligo-ovulation/anovulation(menstrual dysfunction), hyperandrogenism and appearance of polycyclic ovaries in ultrasound look like the pearl string ${ }^{(5)}$.

\section{Anti -Mullerian hormone:-}

Anti-Mullerian hormone(AMH)also define as Mullerian-inhibiting substance,Mullerian inhibiting factor and Mullerian-inhibiting hormone.It is a glycoprotein dimer,it belongs to the member of the transforming growth factor beta superfamily, it is produced from the 36th week of gestation, by the granulosa cells of growing follicles of the ovary,primary, 
secondary,preantral and antral,start produced at elevated values by the last two and has an a specific role in the evolution and maturation of follicles ${ }^{(6)}$.It has two main mechanisms of ovarian dysfunction by disrupting folliculogenesis through:suppress the initial induction of primary follicles from primordial follicles, and suppress the responsiveness of antral follicles to (FSH) through period induction (Fig.1).

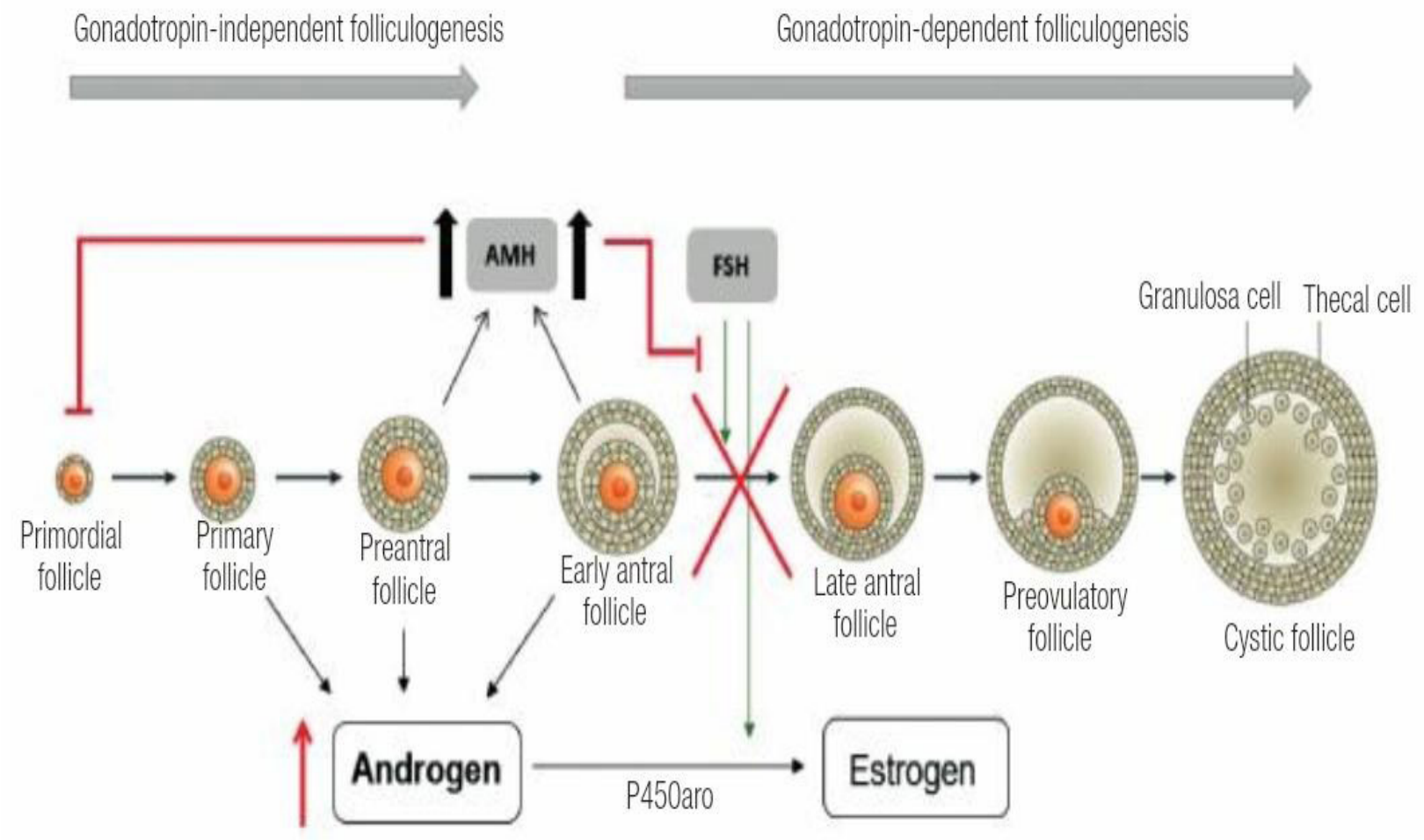

Figure(1): Anti-Mullerian hormone(AMH)and folliculogenesis ${ }^{(7)}$.

The AMH stops the premature exhaust of follicle $\mathrm{e}^{(7)}$. $\mathrm{AMH}$ level higher value at age 25 years,after that decreased to the menopause ${ }^{(6)}$.Circulating AMH levels in serum is high two or three times in the patients with PCOS than healthy women,and not influenced by the menstrual cycle nor changed through the use of oral contraceptives, thus it can be applied as a potent parameter for detection PCOS .AMH measurement is valuable because, it can be useful in predicting ovarian hyperstimulation,multifollicular complications and may be a novel marker for ovarian aging as well as evaluating treatment efficacy in PCOS.The starting of folliculogenesis is suppressed because increased values of $\mathrm{AMH}$, in women with PCOS, increased AMH value have harmful role in disruption of ovarian physiology and worse fertility outcomes ${ }^{(8)}$.AMH also block the action of the aromatase enzyme,suppose that the AMH participate in the severity of PCOS,therefore can AMH may can be applied as a delegate parameter of classical hyperandrogenism.AMH has two receptors type 1 receptor(AMHR-I)is a non specific and type two receptor(AMHR-II)is specific by the AMHR2 gene present on the AMH target organs such as mullerian duct and granulosa cells of ovary,binding of AMH to AMHR2 inhibit follicle development by suppressing recruitment of primordial follicles into the pool of developing follicles ${ }^{(9)}$.

AMH protein expression initiate at the primary follicle phase,very raise expression is determined in FSH-dependent preantral and small antral follicles of $<4 \mathrm{~mm}$ in diameter and $\mathrm{AMH}$ reduced and absent in follicles larger than $8 \mathrm{~mm}$. The distinctive feature of PCOS is failure of follicular development,causing anovulation and aggregation of preantral and small antral follicles, which may be contributed to high introduction of $\mathrm{AMH}^{[(10)}$. Hyperandrogenism quickens preantral and antral follicle growth in the ovary,and expanded $\mathrm{LH}$ causes in premature luteinization resulting follicular arrest leading elevated values of AMH.It is likewise proposed the obesity had an extra prohibitory impact on gonadotrophin discharge because of an expansion in convert androgens to estrogens in fat tissue bringing about the concealment of LH and the subsequent restraint 
of the dominant follicle ${ }^{(11)}$.

level of AMH in women benefit as a biomarker of ovarian storage and refer to the small follicles cannot growth,if low in the clinical state of decreased ovarian store,indicating that presence a little number of follicles in the ovary.AMH block the premature evolution of follicles and eggs,this happen by decreasing the number of FSH receptors on ovaries and preventing the premature egg maturation by FSH in each cycle ${ }^{(6)}$.

Other importance of this hormone in various pathological conditions of ovaries not only the diagnosis and follow up of ovarian tumors of granulosa cell origin, but also prognosis of ovarian hyperstimulation syndrome and $\operatorname{PCOS}^{(12)}$.

AMH prevent the secretion of FSH and impact on growth of follicle by suppress the expression of aromatase enzyme dependent FSH and luteinizing hormone (LH) receptor.In PCOS ladies, there is a partition that keep the follicles to turn into the predominance follicle.In addition to the reduced value of FSH,increase values of AMH slower the responsiveness of follicles to FSH,therefore the follicles stop development into a predominance follicle, that cause an aggregation of several small antral follicles less than (9) $\mathrm{mm}$ in diameter in the ovary ${ }^{(13)}$.

\section{Anti -ovarian Antibody: -}

Polycystic ovarian syndrome is the endocrinopathy and disturbance that cause menstrual impairment and infertility through propagative age,genetic and hormonal status have important function in the pathogenesis of PCOS.Decrease secretion of progesterone in PCOS give rise to over-stimulation of immune system that increase oestrogen secretion that lead to different autoantibodies, have been reported in PCOS, for such as anti-nuclear antibodies(ANA), anti-thyroid,antihistone,anti-islet cell and anti-ovarian antibodies $(\mathrm{AOA})^{(14)}$.AOA is a group of auto-antibodies against ovarian antigens, include anti-oocyte plasma,oocyte membrane(zona pellucida), different parts of the ovary granulosa,theca interna and lutein follicular cells.Many causes for AOA formation,may be include chronic inflammation of the ovaries, laparoscopic abdominal surgery, the collection of oocytes for assisted reproductive techniques(ART)and also the presence of auto-antibodies against human heat-shock protein $90-\beta$ (anti-HSP90 $\beta$ )in the sera of infertile women, this protein causes ovarian autoimmunity and is considered to be a marker of ovarian damage also associated with $\mathrm{POF}^{(15)}$. AOA disrupt the development and function of oocytes and result a decline in the fertilization rate,thus they could likewise be an autonomous marker for possible ovarian failure.The AOA have antagonistically influence on egg quality or hinder the luteal stage and implantation. Presence of AOA either against tissues ovary or oocytes and presence of these AOA proposes detection of autoimmune process that might be the primary or secondary response to an ovarian combination, found high level of AOA in women after follicular puncture of unsuccessful in vitro fertilization(IVF) trials may be in charge of for the pathophysiology of unprompted miscarriages,additionally found with, endometriosis, other reproductive disorders such as adrenal failure,polyglandular autoimmune disorders, unexplained infertility and PCOS associated with antiovarian autoimmunity ${ }^{(16)}$.Another cause in the production of anti-ovarian antibodies may be an autoimmune process of POF.The antiovarian antibody are reported in premature ovarian insufficiency(POI),more found of an $\mathrm{AOA}(30-67 \%)$ autoantibodies has been reported in POI patients.A few antibodies in the aggregation of AOA are thought to connect with an immediate activity on ovarian tissue, while others have no such impacts, comparably to autoantibodies in the other autoimmune diseases, therefore it is conceivable that few various antigens are include in the ovarian autoimmunity on the grounds that both ovarian cell and zona pellucida,oocyte antibodies have been documented. The production of AOA in some cases was activated by hormonal incitement of ovaries and coordinated against(LH)receptors, or human chorionic gonadotrophin(HCG)receptors, or both of them, the AOA appraisal,demonstrates that AOA are particular coordinated to theca interna cells.Ovarian antibodies have been appeared to be available in infertile ladies in spite of the fact that demonstrating ordinary level of FSH and inhibin-B,recommending that ovarian antibodies are free indicators of potential of autoimmune ovarian defeat, the pathological importance for presence ovarian antibodies to different cell parts of the ovary can (a)diminish fertilization rates (b)decline pregnancy rates (c)create a poor reaction to gonadotropin prompting (d) influence egg and embryo improvement (e)could be in charge of implantation defeat ${ }^{(17)}$.

\section{Materials and Method}

\section{$\underline{\text { Subjects }}$}

The present study consist of 120 women (80 
PCOS patients and 40 control) attended from Al-Furat teaching hospital and fertility center of Al-Sadder medical city in Al-Najaf province.They were seen from(June/2018- October/2018).All these patients and healthy control were examined for PCOS diagnosis by ultrasound,measuring parameters including $\mathrm{AMH}$ and AOA. The AMH detected by (ELFA) technique by using minividas instrument (Biomerieux,France)and AOA measured by ELISA technique (Human,Germany).

\section{Sample collection:}

Venous blood samples $(5 \mathrm{~mL})$ were collected from all patients and healthy controls by using disposable syringe, the specimens were taken $\operatorname{during}\left(2^{\text {nd }} 7^{\text {th }}\right)$ day of the menstrual cycle from those of patients and healthy control.The samples were collected by venous puncture and pushed slowly into a jel tubes, then centrifuged directly by centrifugation at ( $4000 \mathrm{rpm})$ for 10 minutes. Serum of AMH was measured immediately before stored and the remaining of the sera were stored at deep freeze in disposable plain plastic tubes, until the time of the analysis of AOA.

\section{A. Inclusion criteria:}

All patients must fulfill the international diagnostic criteria for PCOS.

All patients and control group should be more than (15 and less than 40) year.

The PCOS is diagnosed for not than one year ago.

\section{B. Exclusion criteria:}

Patients that do not fulfill the international diagnostic criteria for PCOS.

Any diagnosed case of PCOS under current medication.

Control with a previous history of PCOS and recovered

Patients of unexplained causes of infertility

Patients with other chronic disease .

\section{Results and Discussion}

Table (1) : Levels of AMH and AOA in sera of studied groups .

\begin{tabular}{|l|l|l|l|l|l|}
\hline \multirow{2}{*}{ Parameters } & Patients $\mathbf{n}=\mathbf{8 0}$ & Control $\mathbf{n}=\mathbf{4 0}$ & Statistics $\mathrm{t}$ test & p value & Sig. \\
\cline { 2 - 5 } & Mean \pm SD & Mean \pm SD & & & \\
\hline AMH & $7.75 \pm 2.49$ & $2.63 \pm 1.21$ & $\mathrm{t}=12.28, \mathrm{df}=118$ & 0.001 & HS \\
\hline AOA & $4.92 \pm 2.52$ & $4.52 \pm 0.29$ & $\mathrm{t}=4.875, \mathrm{df}=118$ & 0.08 & NS \\
\hline
\end{tabular}

The level of AMH in patients and healthy control.

Table(1)and figure(2)explained a highly significant elevation $(\mathrm{P}<0.01)$ in the mean concentration of AMH in sera of patients in comparison with the mean serum concentration of control [AMH( $7.75 \pm 2.49 \mathrm{ng} / \mathrm{mL}) \operatorname{and}(2.63 \pm$ $1.21 \mathrm{ng} / \mathrm{mL})$ ], respectively with a highly significant difference $(\mathrm{P}<0.01)$. At an optimal cut-off value of $(1.19) \mathrm{ng} / \mathrm{mL}$, AMH showed the sensitivity and specificity as $61.0 \%$ and $85.0 \%$ respectively, with a AUR( 0.575$)(95 \% \mathrm{Cl}: 0.471-$ 0.679 ), as showed in table(2)below and figure(3)below. The current study appeared increased result of AMH in $(55.0 \%)$ of PCOS patients more than normal value.

Table (2): ROC for studied parameters.

\begin{tabular}{|l|l|l|l|l|l|}
\hline Parameters & Cutoff & AUR & $\mathbf{9 5 \% C I}$ & Sensitivity\% & Specificity\% \\
\hline AMH & 1.19 & 0.575 & $0.471-.679$ & 61 & 85 \\
\hline AOA & 1.5 & 0.651 & $0.552-0.750$ & 88 & 85 \\
\hline
\end{tabular}




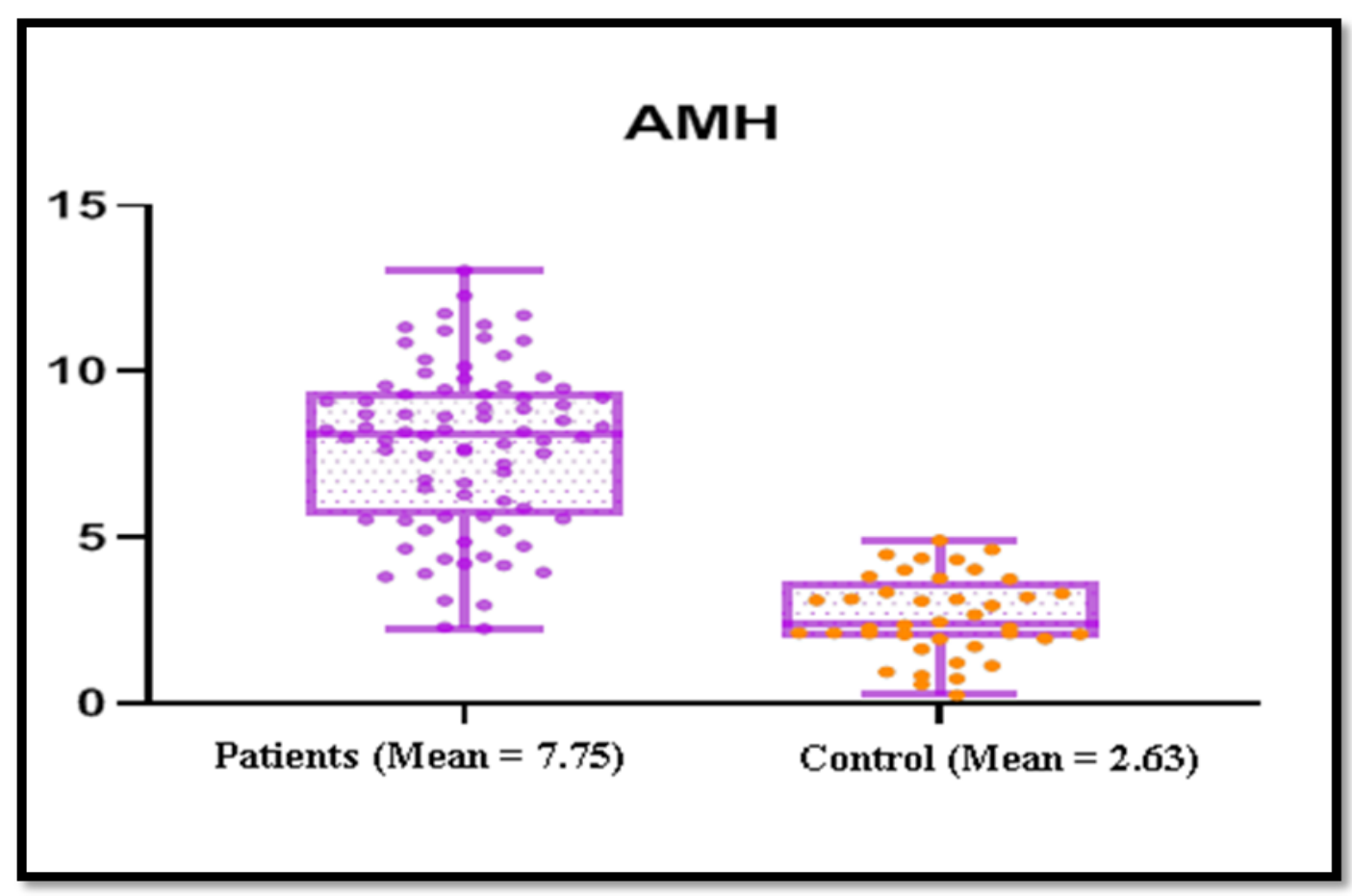

Figure (2): Boxplot of AMH levels in studied groups.

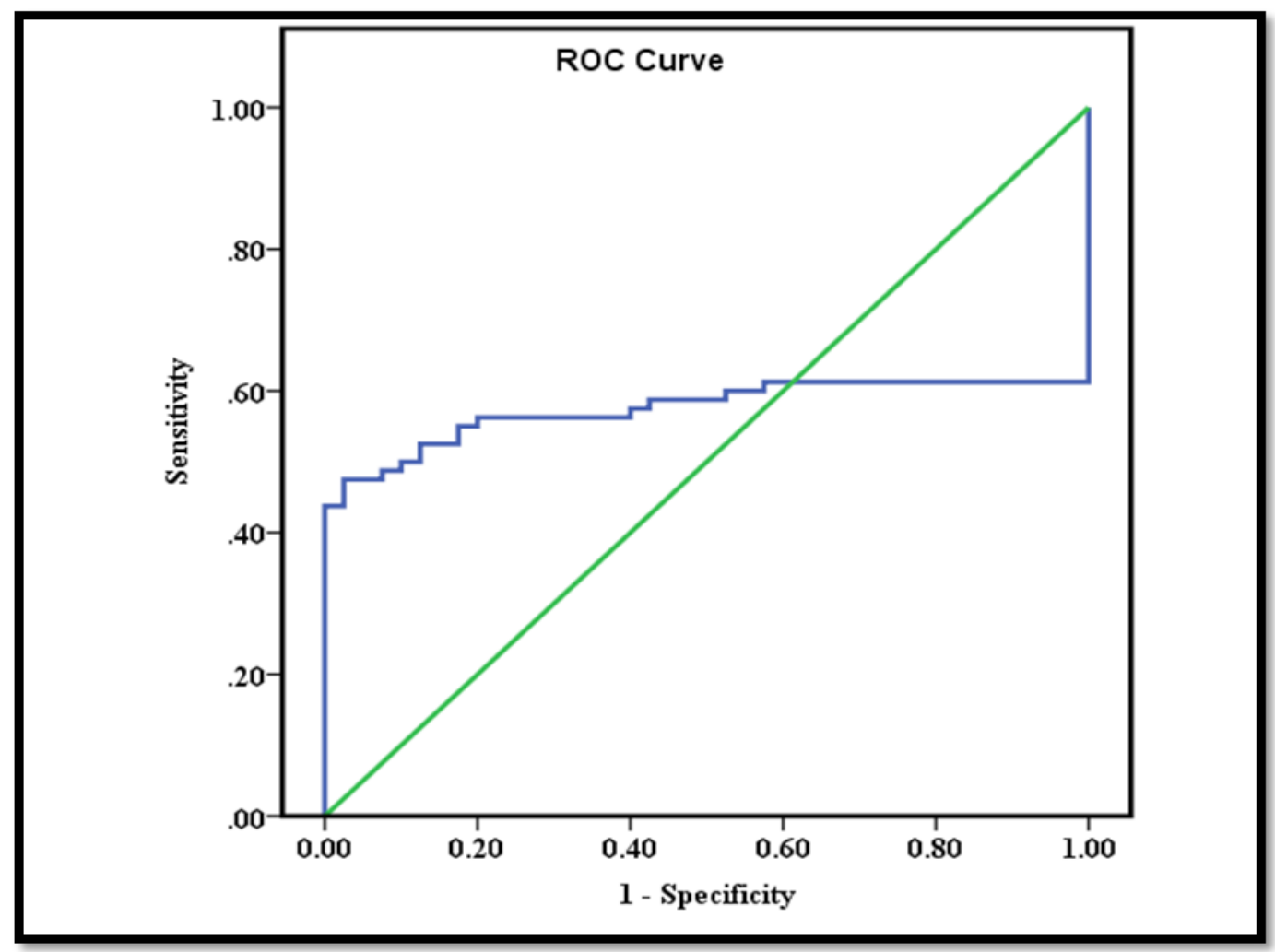

Figure (3): ROC curve analysis of AMH to discriminate the studied groups.

This study agreed with recent Iraqi study finished by(Mohaisen et al.,2019)(18)in Misan city.Several recent studies confirmed by(Deshmukh et al.,2019)(19) in England and by (Cela. et al.,2018) ${ }^{(20)}$ in Italy, that reported increased AMH level in PCOS ladies than healthy ladies. The increase level of serum AMH in PCOS refer to the fact that AMH level indicate the count 
of small antral follicles and increased secretion of AMH per follicle and therefore the increased AMH expression has been indicated in the phase of preantral and small antral follicle size (4-8mm) and dissolve in follicle size more than $9 \mathrm{~mm}^{(21)}$.

The increase of production of AMH prompt the decrease in the sensitivity of follicles to FSH at levels of receptors, which is very necessary for growing of this follicles, it leads to an increase of the numbers of antral follicles on the detriment of their size and the number of small antral follicles size $(2-5 \mathrm{~mm})$ increases, therefore failure the selection of the dominant follicle and anovulation occur with oligo or amenorrhea ${ }^{(22)}$.

Other cause for elevation AMH associated with the raise insulin levels that participate to hyperandrogenemia in (PCOS) that result a defect in folliculogenesis,then participate of polycystic morphogenesis of the ovaries and increased AMH level than normal.An increase level of $\mathrm{AMH}$ is indicate either to inflexible anovulation or refer to ovarian hyperstimulation syndrome.Therefore, it is suggested that the apply of insulin sensitizers will decrease insulin resistance,hyperandrogenemia, and also lower AMH level in serum and will alter the anovulatory cycles to ovulatory ${ }^{(23)}$.

Level of AOA in sera of patients and healthy control.

The serum $\mathrm{AOA}(\mathrm{U} / \mathrm{mL})$ in table(1)and figure(4) illustrated a non significant difference $(\mathrm{P}>0.01)$ in the mean concentration of AOA in sera of patients[serum $\operatorname{AOA}(4.92 \pm 2.52) \mathrm{U} / \mathrm{mL}]$ in comparison with mean sera concentration of control group[serum AOA( $4.52 \pm$ $0.29) \mathrm{U} / \mathrm{mL}$.At an optimal cut-off value of (1.5) $\mathrm{U} / \mathrm{mL}$, AOA showed the sensitivity and specificity of $88 \%$ and $85 \%$ respectively, with a AUR( 0.651$)(95 \% \mathrm{Cl}$ : $0.552-$ 0.750 ), as showed in table(2)above and figure(5)below.

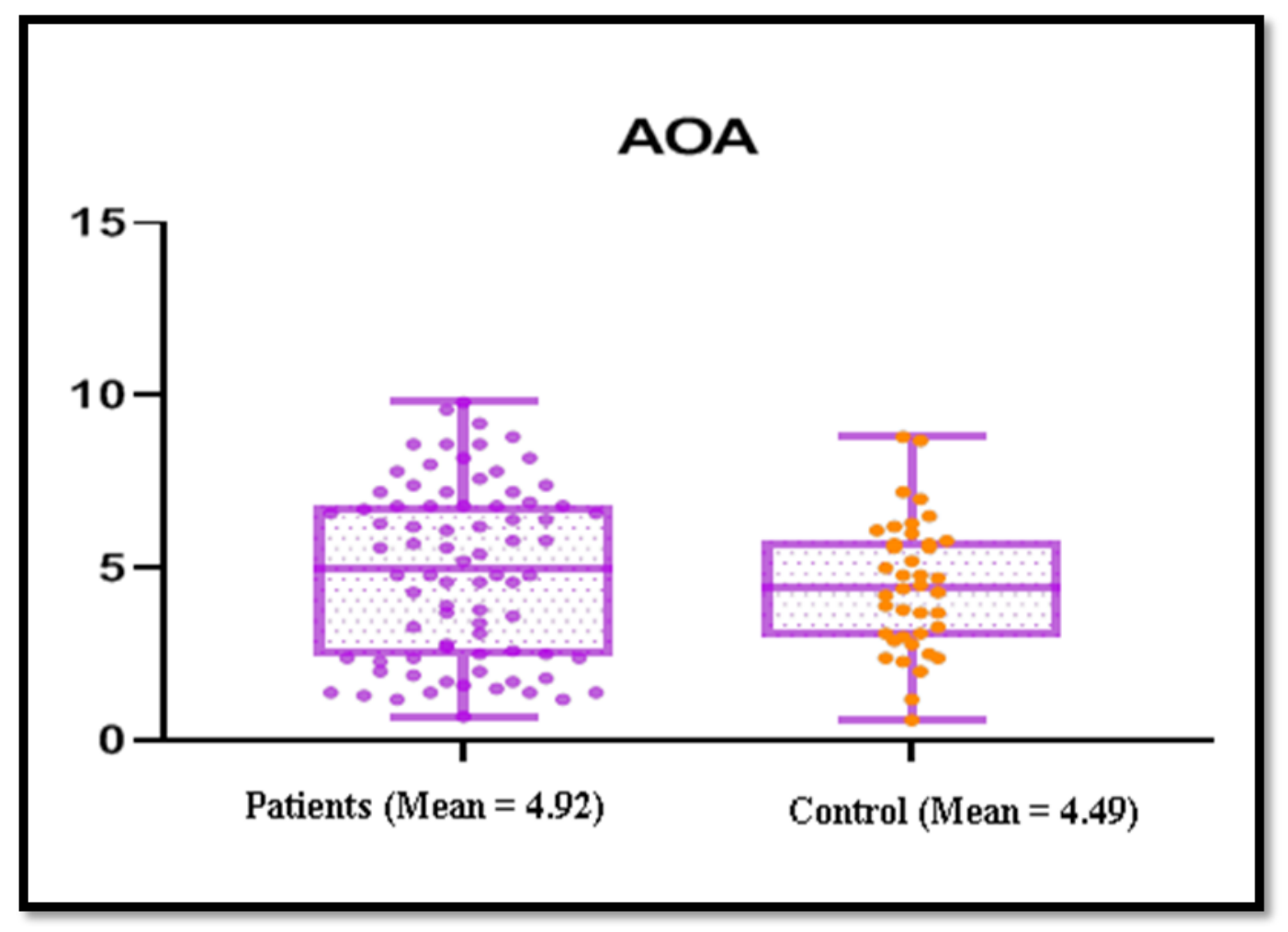

Figure(4): Boxplot of AOA level in studied groups. 


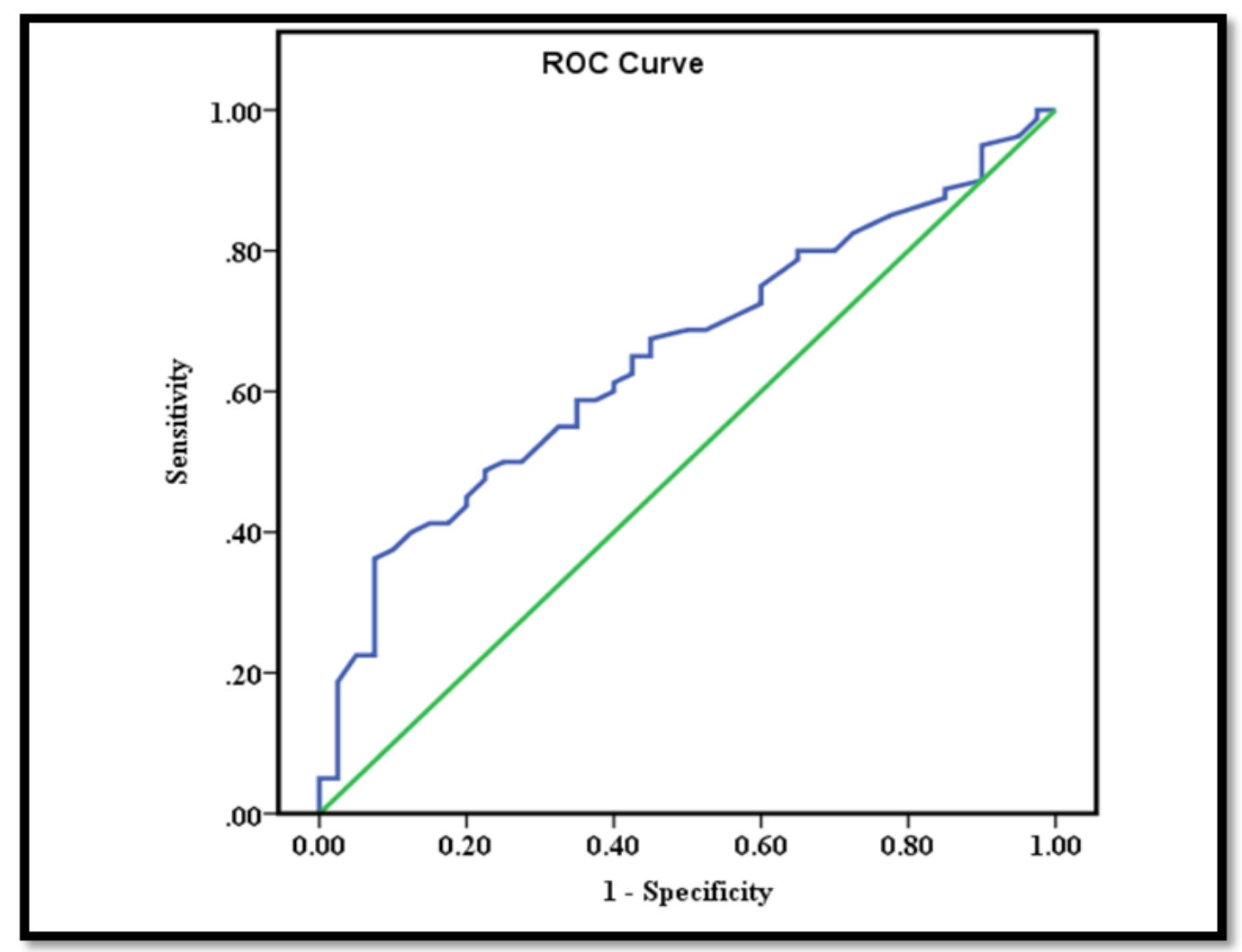

Figure(5): ROC curve analysis of AOA to discriminate patients from control.

The result of this study explained no correlation between the AOA and PCOS, where all the concentration of the AOA within normal value in patients and healthy control and no significance difference between them.

The studies about the relationship between AOA and PCOS very little,although the AOA is very important analytical tool to detect and explain the mechanism of disease development, evolution and resultant disrupt in the ovary.

The current result of this study agreed with study in USA occurred by(Aritro et al.,2014) ${ }^{(24)}$ which failed in different investigations to affirm presence of AOA in PCOS ladies.The study done by(Beata et al.,2016) ${ }^{(25)}$ in Poland confirmed a high prevalence of anti ovarian antibodies(AOA)about (30-67\%) has been observed in patients with premature ovarian failure(POF).

Other study accomplished by (Pires et al.,2015)(26) in USA reported presence of AOA as an auto immune antibody,after failure several attempts of in vitro fertilization (IVF) and also presence of it causes reduce IVF success.

The reason of not detect the presence of high level of AOA in PCOS patient s may be due to presence hyperandrogenemia, which considering a protective function, high levels of androgen play a role in PCOS cases and prevent the development of autoimmune diseases ${ }^{(27)}$.

Ethical Clearance: The Research Ethical Committee at scientific research by ethical approval of both environmental and health and higher education and scientific research ministries in Iraq

Conflict of Interest: The authors declare that they have no conflict of interest.

Funding: Self-funding 


\section{References}

1. Azziz R,Carmina E,Chen Z,Dunaif A,Laven JS,Legro RS.Polycystic ovary syndrome. Nat Rev Dis Primers.2016;2:16057.

2. Raiane PC,Tania AS,Bachega T,Berenice BM,Larissa G.An update of genetic basis of PCOS pathogenesis.Arch Endocrinol Metab.2018 ;62(3):352-61

3. Zore T,Lizneva D,Brakta S,Walker W,Larisa S,Azziz R.Minimal difference in phenotype between adolescents and young adults with polycystic ovary syndrome.Fertil Steril.2019;(111):389-96.

4. Shaaban Z, Khoradmehr A,Jafarzadeh S MR,Tamadon A.Pathophysiological mechanisms of gonadotropins-and steroid hormones-related genes in etiology of polycystic ovary syndrome. Iran J Basic Med Sci.2019;22(1):3-16.

5. Rotterdam ESHRE/ASRM-Sponsored PCOS Consensus Workshop Group. Revised consensus on diagnostic criteria and long-term health risks related to polycystic ovary syndrome (PCOS).Hum Reprod.2003;(19):41-47.

6. Iram S,Sheikh I,Arif A,Roohi A,Sabhiya M.AntiMullerian hormone as a diagnostic marker in women with polycystic ovary syndrome.Indian $\mathrm{J}$ of Obst and Gynecol Res.2016; 3(4):303-306.

7. Crespo RP,BachegaT,Mendonca BB, GomesLG.An update of genetic basis of PCOS pathogenesis.Arch Endocrinol Metab.2018;62(3):352-361.

8. Parahuleva N,Pehlivanov B,Dimitrakova E,Malinova M, Mladenova M.Anti-Mullerian hormone its role in the pathogenesis of the polycystic ovary syndrome.Akush Gynecol.2012;51(6):22-26.

9. Zehra J,Syeda S, Khalid A, Rabia M.Anti-Mullerian hormone:Above and beyond conventional ovarian reserve markers.Hindawi pub corporation Dis mark.2016;1-9.

10. Teede H,Misso M,Deeks A,Moran L,Stuckey $\mathrm{B}$, Wong J.Assessmentandmanagementofpolycystic ovary syndrome:Summary of an evidence-based guideline.Med J Australia.2011;195(6):68-69.

11. Cassar S,Teede HJ,Moran LJ,Joham AE,Harrison CL,Strauss BJ,Stepto NK.Polycystic ovary syndrome and anti-mullerianhormone:role ofinsulin resistance,androgens,obesity and gonadotrophins. Clin Endocrinol.2014;81(6):899-906.
12. Grynnerup A,Lindhard A,Sorensen S.The role of antiMullerian hormone in female fertility and infertility-an overview.Acta Obstet Gynecol Sci.2019;91(11):1252-60.

13. Wiweko B,Maidarti M,Priangga MD,Shafira N,Fernando D,Sumapraja K,Natadisastra M, Hestiantoro A.Anti-mullerian hormone as a diagnostic and prognostic tool for PCOS patients. J Assist Reprod Genet.2014;31:1311-1316.

14. Petrikova J,Lazurova I.Ovarian failure and polycystic ovary syndrome.Autoimmunity Rev.2012;11(6):471-478.

15. Bobak L,Bobakova D,Vaczy Z,Rosocha J,Halagovec A.Incidence of antibodies in women after failure of assisted reproduction.Indexed and abstracted in Sci citation index expanded and in $\mathrm{J}$ citation Rep /Sci. Edit.2014;115(3):145-149.

16. Kaushiki K,Purvi M,Asmita C.Autoantibodies:Key Mediators of Autoimmune Infertility.Indian Council of Med Res and Dept of Biotechnol Govt of India.2018;1-25.

17. Pires ES.Multiplicity of molecular and cellular targets in human ovarian autoimmunity. J Assist Reprod Genet.2010;27:519-524.

18. Mohaisen IK.Serum levels of anti mullerian hormone, leptin,T3,T4 and TSH in women with polycystic ovary syndrome in Iraq.Indian J of Public Health Res\& Development.2019;10(2):745-751.

19. Deshmukh H,Papageorgiou M,Kilpatrick E,Atkin S,SathyapalanT.Development of a novel risk prediction and risk stratification score for polycystic ovary syndrome.Clin Endocrinol.2019;90(4):162-169.

20. Cela V,Obino ME,Alberga Y,Pinelli S,Sergiampietri C,Casarosa E,Simi G, Papini F,Artini PG.Ovarian response to controlled ovarian stimulation in women with different polycystic ovary syndrome phenotypes.Gynecol Endocrinol.2018;34(6):518-523 .

21. Bhide P,Dilgil M,Gudi A,Shah A,Akwaa C,Homburg R.Each small antral follicle in ovaries of women with polycystic ovary syndrome produces more antimullerian hormone than its counterpart in a normal ovary:an observational cross sectional study.Fertil Steril. 2015;103(2):537-541.

22. Alfatlawi WR.Study the Effect of Interleukin 36 Gamma and AMH in Iraqi Women with PCOS.A1Mustan J of Sci.2017;28(3):151-156. 
23. Chhabra N,Malik S.Effect of insulin sensitizers on raised serum anti-mullerian hormone levels in infertile women with polycystic ovarian syndrome.J Hum Reprod Sci. 2018;11(4):348-52.

24. Aritro S,Vitaly A,David H,Norbert G.Endocrine autoimmune diseases and female infertility.Nat Rev Endocrinol.2014;10:37-50 .

25. Beata K.Autoimmune premature ovarian failure. Menopause Rev.2016;15(4):210-214.
26. Pires E.Consider Anti-Ovarian Antibody Testing for ART:a Parameter to Improve the Success Rate of Your Clinic.Austin J In Vitro Fertili.2015;2(3):1022.

27. Hemmatabadi M,Shirzad N,Saeedinia A,Rashidian H.Polycystic Ovary Syndrome Combined with Type II Polyglandular autoimmune Syndrome. Case Rep Clin Pract.2018;3(2):60-62. 